\title{
3.2. EfiKronik ikerkuntza programa: gaixotasun kronikoa dituzten gaixoentzat ariketa fisikoaren eraginkortasuna
}

\author{
Nere Mendizabal Gallastegui \\ Bizkaiko Lehen Arretako Ikerkuntza Unitateko erizaina. \\ nere.mendizabalgallastegui@osakidetza.eus
}

\section{Sarrera}

Imajina dezagun arnas gaixotasun kronikoak, neoplasiaren bat edota gaixotasun mentalak dituzten guztiek jasotzen dituztela ariketa fisikoak ekar ditzakeen onurak. Nola hobetuko lirateke euren bizi kalitatea eta autonomia? Nola murriztuko lirateke euren sintomak, konplikazioak eta berriz gaixotzeak?

Froga zientifiko sendoek adierazten dute ariketa fisikoa eraginkorra dela gaixotasun kronikoak prebenitu eta tratatzeko. Zenbait kasutan, ariketa fisikoa -interbentzio moduan- interbentzio farmakologikoa bezain eraginkorra da, edo are eraginkorragoa, hilkortasuna murrizteko, bizikalitatea, funtzio fisikoa eta psikosoziala areagotzeko eta gaixotasun kronikoak dituzten pertsonen autonomia hobetzeko [1-4]. Hala ere, ebidentzia horiez aparte,pazienteen \% 50ek baino gutxiagok baino ez dute jaso ariketa fisikoak dakarren onuraren inguruko aholkuren bat euren profesionalen eskutik, eta gutxiengo batek adierazi du noizbait ariketa fisikoa preskribatu diotela [5, 6]. Efikronik-ek gaixo horiei lagundu nahi die beren osasuna kudeatzen, aktibo eta autonomo mantendu daitezen ariketa fisikoaren eta ohitura osasuntsuen bidez. Izan ere, hori da euren pronostiko eta sintomak kontrolatzeko gakoa.

Munduan, osasun sistema gutxi batzuek soilik eskaintzen dituzte ariketa fisiko gainbegiratuko programak. Konkretuki, minbizia gainditu eta eraginkortasun klinikoa baldintza errealetan mantendu dutenentzako programa hauek daude (Evidence Based Interventions, EBIs): LIVESTRONG (YMCA, Estatu Batuak) [7], LifeNow (Cancer Council Western, Australia) [8] eta FitSTEPS forLife (Hunt Regional Healthcare, Hego Karolina, Estatu Batuak) [9]. Eraginkortasun frogatua duten beste interbentzio kliniko batzuekin gertatzen den bezala, beste osasun testuinguru batzuetan, ariketa fisikoko programak ez dira modu iraunkor eta orokorrean islatzen eguneroko praktika klinikoan. .

Ez islatze horren ondoriozkoa da faktore kliniko eta inplementazio faktore asko bateratuak izatea ala "traslazio bretxak" egotea ("evidence-to-practicegap" gisa ezaguna literaturan). Alde batetik, gehiago ikertu behar da ariketa fisikoa zein baldintzatan den eraginkorragoa jakiteko. Adibidez, funtsezkoa da osasunean onaurak dakartzan ariketa fisikoaren dosi minimoa zein den ezagutzea [2]. Gainera, beste arazo kliniko hau ere ikusi da: atxikipenak behera egiten du gainbegiratutako ariketa fisikoko programak amaitutakoan, gaixoek zailtasunak dituztelako ariketa fisikoarekin jarraitzeko euren komunitateko baliabideekin [11, 12].

Beste alde batetik, inplementazio faktoreekin erlazionatutako oztopo anitz daude, eta horrek zaildu egiten du programa horiek praktika klinikora eramatea (lan asistentzialeko gainkarga, 
profesional batzuen eszeptizismoa ariketa fisikoa tratamendu moduan erabiltzeko, zenbait osasun zerbitzuren predisposizio eskasa antolakuntza aldatzeko...) [13].

Osasuna sustatzeko interbentzioen translazioa oraindik konplexuagoa da, osasun sistemak gaixotasunaren tratamendura egokituta daudelako (prebentziora baino gehiago), baita interbentzio farmakologikoetara ere (ohitura osasuntsuen sustapenera baino gehiago).

Badira jada 10 urte Lehen Mailako Arretako Bizkaiko Ikerkuntza Unitateak "Ariketa fisikoa eta gaixotasun kronikoak" ikerketa ildoa abian jarri zuela honako asmo honekin: ebidentziak lortzea erizainek gainbegiratutako ariketa fisikoko programek Osakidetzako lehen mailako zentroen sare batean duten eraginkortasunaren inguruan [14-18].

\section{Helburuak}

\subsection{Helburu klinikoak}

Lehen Mailako Arretako erizain baten gainbegiratzepean, EfiKroniK ariketa fisikoko programa berritzaileak gaixotasun ezberdinak dituzten pertsonengan (minbizi solidoak, hematologikoak, birikietako gaixotasun buxatzaile kronikoa eta eskizofrenia) zer-nolako efektua duen zenbatetsi nahi da, ohitura osasuntsuak sustatzeko interbentzio ohikoekin alderatuta (ariketa fisikoa, dieta orekatua eta tabakoa erretzeari uztea).

Eraginkortasuna honela adierazten da:

- Ahalmen funtzionala (testen bidez, oinez 6 minutu edo $400 \mathrm{~m}$ eginda).

- Bizi kalitatea eta erabilpena (gaixotasunaren araberako galdetegi orokor eta zehatzen bidez).

- Sintomatologia, alderdi psikologikoak eta sozialak.

- Parametro analitiko zehatzak (adiponektina, PCR, TNF- $\square$ II-1, II-6, BDNF).

*Ikerketa abiarazteko momentuan eta 3, 6 eta 12 hilabeteren buruan neurtuko dira emaitza guztiak.

\subsection{Inplementazio-helburuak}

- Pazienteek EfiKroniK programaren erabilpenari eta egokitasunari buruz duten pertzepzioa deskribatzea, hala nola euren itxaropenak eta gogobetetzeak.

- EfikroniK programa era orokortu, iraunkor eta jarrai batean ezartzeko erraztasunak eta zailtasunak ezagutzea, hala nola pazienteek programarekin duten atxikimendua.

\section{Metodologia}

EfiKroniK entsegu hibrido bat da, 2 talde paralelotan egiten dena. Kasu honetan, 370 pertsonak hartuko dute parte, honako lau gaixotasun hauen arabera estratifikatuak: minbizi solidoak (100), hematologikoak (70), birikietako gaixotasun buxatzaile kronikoa (100) eta eskizofrenia (100). 


\subsection{Inklusio irizpideak}

- 18-75 urte bitarteko pertsonak

- Koloneko, bularreko edo birikietako minbizi solidoak IVE estadioan, lehenengo lerroko kimioterapia tratamenduarekin

- $\mathrm{PS}<=1$

- Hemopatia goiztiarra transplante autologoarekin edo linfoma ez lokalizatuak immunoterapiako tratamenduarekin

- Eskizofrenia

- Birikietako gaixotasun buxatzaile kronikoa, 3-7ko BODE indizearekin eta egonkortasun klinikoarekin

- Giltzurrun, gibel eta hematologia funtzio egokia

- Hemoglobina $>10,>50.000$ plaketa, $>1.000$ neutrofilo

- Karfnosky $>60, E C O G \geq 1$

\subsection{Esklusio irizpideak}

- Garun metastasiak

- Haustura arrisku handia hezur metastasiengatik

- Ezegonkortasun emozionala

- Afektazio kardiorrespiratorioa edo infekzio ez kontrolatuak

- Birjaustea edo gaixotasun hematologikoaren progresioa

- Komunikazio alterazioak, datuen bilketa debekatzen dutenak; edo hondatze kognitibo garrantzitsua

- Bronkiektasiak eta birikietako gaixotasun buxatzaile kronikoen ezberdinak diren birikietako alterazioak

- Ariketa fisikoko programa gauzatzea zailtzen edo galarazten duten beste komorbilitate batzuk

- Tentsio arterial ez-kontrolatua (TAS > 200 edo TAD > 110)

- Programaren interbentzioa baino intentsitate, maiztasun eta iraupen handiagoko ariketa fisikoa egitea erregulartasunez.

\subsection{Interbentzio taldea}

\section{Lehenengo fasea (3 hilabetez gainbegiratzea)}

Talde honetako pertsonek ariketa fisikoko programa bat jasotzen dute 36 saiotan, eta, 3 hilabetean zehar, intentsitatea pixkanaka igotzen zaie. Gainbegiratzearekin hasi aurretik, paziente bakoitzari lehen balorazioa egiten zaio plan pertsonalizatua zehazteko. Ondoren, pazientea programarekin hasten da berak aukeratutako osasun zentroren bateko kirol laborategian (Etxebarri, Deustu, Lutxana, Algorta edo Buenavista).

Erizain batek edota ariketa fisikoan graduatutako profesional batek gainbegiratzen ditu ariketa fisikoko saioak. Hiru hilabeteotan, pertsonak bakoitzak 3 saio egiten ditu astean: 2 laborategian eta, hirugarrena, osasun zentroaren inguruan. Laborategian egiten diren saioetan, indar muskularra lantzen da pisuekin, eta gaitasun aerobikoa, bizikletan edota ibiltzeko tapizean. 
Saio guztietan gaixoak monitorizatuta daude pultsometro baten bidez, bakoitzak dagokion bihotz frekuentzian lan egin dezan. Saio guztietan ere Borg eskala erabiltzen da, ariketa fisikoa zenbaterainoko gogorra izaten ari den jakiteko.

\section{Bigarren fasea (9 hilabetez jarraipena egitea)}

Pazienteak 3 hilabeteetan ikasitakoarekin jarraitzera animatzen dira; hau da, ariketa fisikoa egiten jarraitzen dute euren komunitatearen ingurunean. Jarraipena urtebetez egiten da, eta emaitzak 3, 6 eta 12 hilabete igarotakoan neurtzen.

\subsection{Kontrol taldea}

Aditu batek ariketa fisikoko plan pertsonalizatu bat preskribitzen dio taldean sartzen den pertsona bakoitzari, bere kabuz bete dezan. Urtebeteko jarraipena ere egiten zaio $(3,6$ eta 12 hilabeteren buruan).

\subsection{Metodologia kualitatiboa}

Ikerketa behaketa kualitatiboa egin da, 3 eztabaida taldetan. Gaixotasun kroniko desberdinak diagnostikatuta dituzten 20 pertsonak hartu dute parte, eta gainbegiratutako ariketa programaren onuradunak izan dira: 10 gaixo hematologiko, tumore solidoak dituzten 3 pertsona eta eskizofrenia duten 7 .

Ondoren, talde bakoitzean sortutako transkripzioen analisia egin da hainbat ikertzaileren artean, planteamendu deduktiboaren eta induktiboaren bidez.

\section{Emaitzak}

\subsection{EfiKroniK kuantitatiboa}

146 paziente sartu dira proiektuan 2019ko abenduaren 30era arte. Lehenengo taulan, 137 pazienteren ezaugarri basalak azaltzen dira, 3 hilabeteko jarraipenaren balorazioa egin eta gero.

Batez besteko adina 54-55 urtekoa da, eta gizon gehiago daude. Gaixo gehienek minbizi hematologikoa dute, eta osasun mentalekoak bigarren tokian daude.

Programaren lehen bisitan, EfikroniK taldekoek kontrol taldekoek baino metro gutxiago egin dituzte 6 minutuko testean; indar-probaren emaitzak ere apur bat hobeak izan dira kontrol taldean.

Galdetegien arabera, EfiKroniK taldekoek laguntza sozial handiagoa dute kontrol taldekoek baino, eta antsietate gutxiago adierazi dute proiektuan sartzerakoan. Bizi kalitateari dagokionez, SF-36 galdetegiarekin neurtutako osagai fisikoan, EfikroniK taldekoen emaitzak apur bat hobeak dira; baina alderantziz gertatzen da osagai mentalean.

Esan beharra dago taldeen artean ez dela ezberdintasun esanguratsurik aurkitu. 
1. taula. Deskriptibo orokorra

\begin{tabular}{|l|c|c|c|}
\hline \multicolumn{1}{|c|}{ Hematologia } & Kontrol & EfiKroniK & p \\
\hline Parte hartzea (\%) & 72 & 65 & \\
\hline \multicolumn{1}{|c|}{ Pneumologia } & & & 0,695 \\
\hline \multicolumn{1}{|c|}{ Onkologia } & $14(47,2)$ & $32(49,2)$ & \\
\hline \multicolumn{1}{|c|}{ Osasun mentala } & $12(16,7)$ & $3(4,6)$ & \\
\hline Gizonak (\%) & $25(34,7)$ & $20(30,8)$ & \\
\hline Adina & $44(61,1)$ & $36(55,4)$ & 0,613 \\
\hline Pisua & $55,47(12,35)$ & $54,25(12,47)$ & 0,564 \\
\hline Koipea & $79,84(22,11)$ & $80,25(20,60)$ & 0,916 \\
\hline Perimetroa & $31,95(7.01)$ & $32,85(7,97)$ & 0,534 \\
\hline Duke & $99,96(16,98)$ & $96,11(22,94)$ & 0,342 \\
\hline 6 minutuko testa & $47,80(8,56)$ & $48,53(8,67)$ & 0,673 \\
\hline Indar maximoa & $437,60(158,15)$ & $399,62(163,57)$ & 0,460 \\
\hline 5 errepikapenen testa & $34,64(11,31)$ & $34,09(10,82)$ & 0,774 \\
\hline GHQ & $14,26(4,37)$ & $15,14(9,87)$ & 0.499 \\
\hline SF36- fisikoa & $3,63(3,26)$ & $3,02(3,16)$ & 0.277 \\
\hline SF36- mentala & $41,26(8,81)$ & $41,50(9,17)$ & 0.878 \\
\hline & $44,85(10,66)$ & $44,02(13,41)$ & 0.695 \\
\hline
\end{tabular}


2. taula. 3 hilabeteren buruan taldeek izandako aldaketa
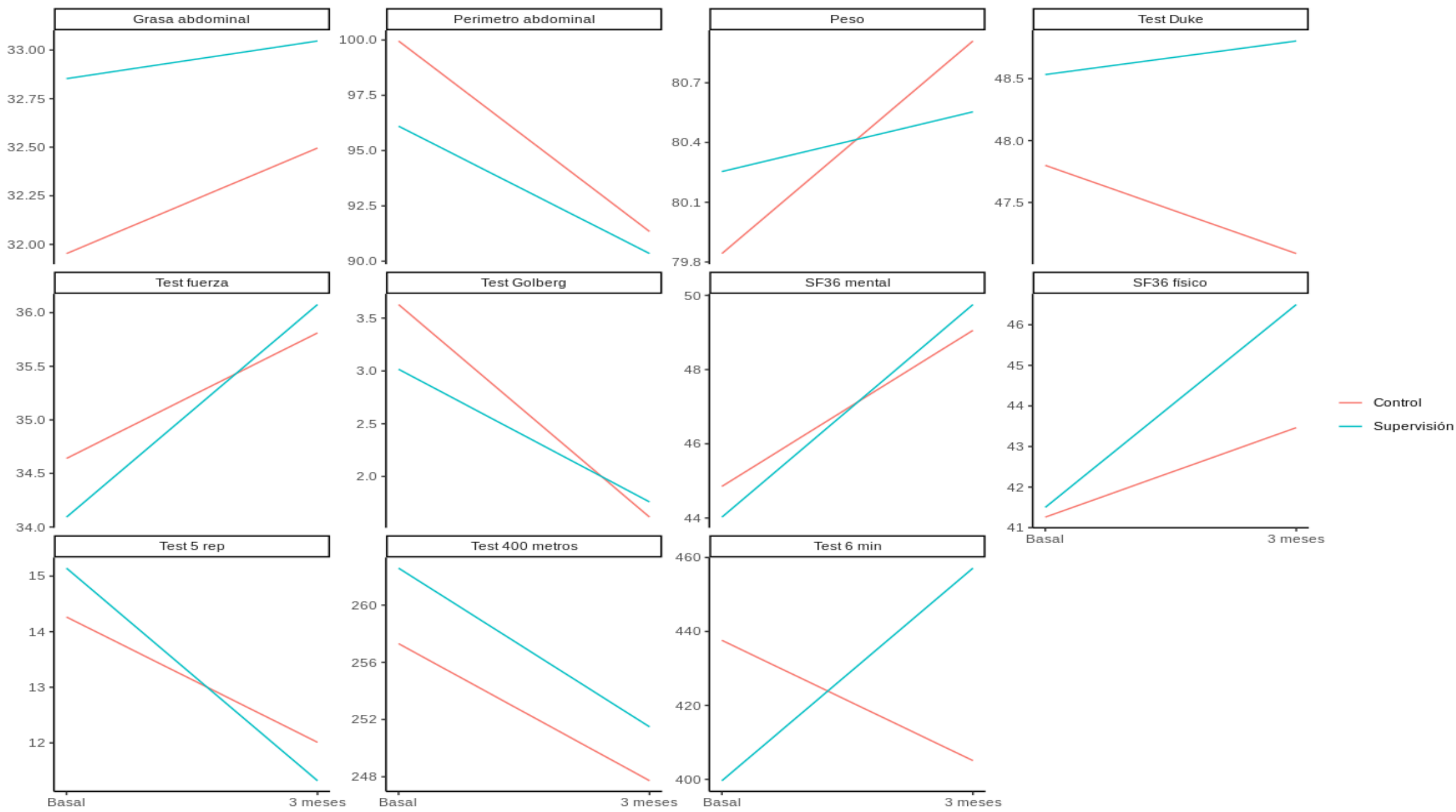
3 hilabetera, aldagai nagusia aztertzean (kapazitate funtzionala), ezberdintasun bat ikusten da 2 taldeen artean, EfiKroniK taldearen alde. Halere, ezberdintasun hori ez da estatistikoki esanguratsua.

Bizi kalitatean ere, bi osagaiei erreparatuta -alegia, bai fisikoa bai mentala- hobekuntza handiagoa da EfikroniK taldeko gaixoengan, nahiz eta kasu horretan ere ez den aurkitu estatistikoki esanguratsua den ezberdintasunik.

\subsection{EfiKroniK kualitatiboa}

Eztabaida taldeetako parte-hartzaileen arabera, EfiKroniK programa lagungarria da bizi kalitatea, gaitasun funtzionala eta ongizate psikosoziala hobetzeko.. Besteak beste, abantaila hauek aipatu dituzte: ingurune sanitario batean programa aurrera eramateko aukera (haien ustez, programa ez litzateke berdina izango beste erakunde motaren batean gauzatu izan balitz, hala nola kiroldegiren edo gimnasioren baten) (i), eta eurenak bezalako esperientziak bizitzen ari diren pertsonekin harremanetan jartzeko aukera (ii).

Eskizofrenia duten pertsonek diotenez, EfiKroniK programari esker, gaixotasunarekin duten esperientzia normalizatu ahal izan dute, Efikronikek gaixotasun mentalekiko estigmak apurtzen dituelako, errutinak sortzen laguntzen duelako eta gizarte elkarreraginen alde egiten.

Halere, partaideek onartu dute euren ariketa fisikoaren maila jaitsi egin dela 3 hilabeteko fasearen ostean, oztopo hauek aurkitu dituztelako:

(i) Partaideekin lotutakoak: tratamenduak gorputzean eragin dizkien aldaketak erakusteko beldurra, ariketa fisikoa gainbegiratzerik gabe egiteko beldurra, konpromisoak eta beharrak ezartzeko zailtasunak, familia beharrak...

(ii) Baliabide komunitarioekin lotutakoak: kiroldegi eta gimnasioak norberaren beharretara egokituta ez egotea, dimentsio soziosanitarioaren gabezia, tratamenduak errendimendura bideratuta egotea eta ez osasunera...

(iii) Gaixotasun kronikoarekin lotutakoak: ondoeza fisikoak, ariketa fisikoarekin talka egiten duten ohitura ez osasuntsuak, tratamenduen ondorioak...

(iv) EfiKroniK programarekin lotutakoak: programaren iraupena ez da nahikoa ariketa fisikoari buruzko informazioa barneratzeko eta autonomia lortzeko.

\section{Ondorioak}

Ariketa fisikoko programak onuragarriak dira gaixotasun kronikoak dituzten gaixoentzat, bereziki erakunde sanitarioetan eta gainbegiratuta egiten direnenean. Halaber, gainbegiratzea bukatutakoan, onura horiek jaitsi egiten dira, hainbat mailatan agertzen diren oztopoen ondorioz.

Euskadiko espazio soziosanitarioan arreta integratua eta etengabea sustatzeko, beharrezkoa da sektorearteko koordinazioa sustatzea; baita inplementazio estrategiak eraikitzea ere, Osakidetzaren zerbitzu zorroan era honetako programak sartu ahal izateko.

Terapia gisa ariketa fisikoa ohikotasunez erabiltzeak posizio aitzindari batean kokatuko luke Osakidetza kronikotasunaren maneiuan. 


\section{Bibliografia}

1. 2018 Physical Activity Guidelines Advisory Committee Scientific Report. Washington DC: US. Dep. of Health and Human Services.

2. Heywood R. Efficacy of Exercise Interventions in Patients with Advanced Cancer: A Systematic Review. Arch Phys Med Rehabil. 2018 Dec;99(12):2595-620.

3. Cormie P. The Impact of Exercise on Cancer Mortality, Recurrence, and Treatment- Related Adverse Effects. Epidemiol Rev. 2017 01;39(1):71-92.

4. Gorczynski P. Exercise therapy for schizophrenia. Cochrane Database Syst Rev. 2010 May 12;(5):CD004412.

5. Datos relevantes de la Encuesta de Salud del País Vasco 2013. 2014.

6. High Quality Care For All NHS Next Stage Review Final Report CM 7432-7432 [Internet, 2019 Feb 14].

Available

from:https://www.gov.uk/government/uploads/system/uploads/attachment_data/file/2288 36/7432.pdf

7. Heston AH. Addressing physical activity needs of survivors by developing acommunity-based exercise program: LIVESTRONG ${ }^{\circledR}$ at the YMCA. Clin J Oncol Nurs.2015 Apr;19(2):213-7.

8. Cormie P. Implementing exercise in cancer care: study protocol to evaluate acommunitybased exercise program for people with cancer. BMC Cancer. 2017 Feb 6;17(1):103.

9. Haas BK. Community-based FitSTEPS for life exercise program for persons with cancer: 5-year evaluation. J Oncol Pract. 2012 Nov;8(6):320-4.

10. Mina DS. Connecting people with cancer to physical activity and exercise programs: a pathway to create accessibility and engagement. Curr Oncol. 2018;25(2):149-62.

11. Pardo A. Effectiveness of a supervised physical activity programme on physical activity adherence in patients with cardiovascular risk factors. Apunts Med Esport. 2014; 49(182): 3744.

12. Martín-Borràs C. A new model of exercise referral scheme in primary care: is the effect on adherence to physical activity sustainable in the long term? A 15-month randomised controlled trial. BMJ Open. 2018 03;8(3):e017211.

13. Grol R. From best evidence to best practice: effective implementation of change in patients' care. Lancet. 2003 Oct 11;362(9391):1225-30.

14. Ortega R. PEPAF group. Cardiorespiratory fitness and development of abdominal obesity. Prev Med. 2019 Jan;118:232-7.

15. Sancho A. Supervised physical exercise to improve the quality of life of cancer patients: the EFICANCER randomised controlled trial. BMC Cancer. 2015 Feb 6;15:40.

16. Ortega R. Supervised exercise for acute coronary patients in primary care: a randomized clinical trial. Fam Pract. 2014 Feb;31(1):20-9.

17. Zuazagoitia A. Rationale and design of a randomised controlled trial evaluating the effectiveness of an exercise program to improve the quality of life of patients with heart failure in primary care: The EFICAR study protocol. BMC Public Health. 2010 Jan 25;10:33.

18. Grandes G. Effectiveness of physical activity advice and prescription by physicians in routine primary care: a cluster randomized trial. Arch Intern Med. 2009 Apr 13;169(7):694-701. 